\title{
Antigens of Borrelia burgdorferi Recognized during Lyme Disease \\ Appearance of a New Immunoglobulin M Response and Expansion of the Immunoglobulin G Response Late in the Illness
}

\author{
Joseph E. Craft, Duncan K. Fischer, Grant T. Shimamoto, and Allen C. Steere \\ Departments of Internal Medicine and Molecular Biophysics and Biochemistry, \\ Yale University School of Medicine, New Haven, Connecticut 06510
}

\begin{abstract}
Using immunoblots, we identified proteins of Borrelia burgdorferi bound by IgM and IgG antibodies during Lyme disease. In 12 patients with early disease alone, both the IgM and IgG responses were restricted primarily to a 41-kD antigen. This limited response disappeared within several months. In contrast, among six patients with prolonged illness, the IgM response to the 41$\mathrm{kD}$ protein sometimes persisted for months to years, and late in the illness during arthritis, a new IgM response sometimes developed to a 34-kD component of the organism. The IgG response in these patients appeared in a characteristic sequential pattern over months to years to as many as 11 spirochetal antigens. The appearance of a new IgM response and the expansion of the IgG response late in the illness, and the lack of such responses in patients with early disease alone, suggest that $B$. burgdorferi remains alive throughout the illness.
\end{abstract}

\section{Introduction}

Lyme disease, which is caused by the tick-borne spirochete, Borrelia burgdorferi (1-3), typically begins in summer with a characteristic skin lesion, erythema chronicum migrans (ECM) ${ }^{1}$ $(4,5)$. Weeks to months later, some patients develop the second stage of the illness characterized by cardiac involvement (6), neurologic abnormalities $(7,8)$, or migratory musculoskeletal pain (5). Weeks to years later, many patients develop frank arthritis, the third stage of the disorder $(4,9,10)$. Joint involvement often occurs intermittently in a few large joints for several years, but it may become chronic with pannus formation and erosion of cartilage and bone $(9,10)$.

Antibody titers to $B$. burgdorferi in Lyme disease patients have been determined previously by indirect immunofluorescence and by enzyme-linked immunoassay (ELISA) $(1,2,11$, 12). The specific IgM response, which is often not detectable during the first 1 or 2 wk of infection, usually peaks during the third through the sixth week, and may persist for months or

This study was published in abstract form (1984. Arthritis Rheum. 27:C2).

Address reprint requests to Dr. Craft. 1986.

Received for publication 9 August 1985 and in revised form 13 January

1. Abbreviations used in this paper: $\mathrm{ECM}$, erythema chromicum migrans; ELISA, enzyme-linked immunosorbent assay; SDS-PAGE, sodium dodecyl sulfate-polyacrylamide gel electrophoresis.

J. Clin. Invest.

(c) The American Society for Clinical Investigation, Inc.

0021-9738/86/10/0934/06 \$1.00

Volume 78, October 1986, 934-939 years after disease onset $(2,11,12)$. Specific IgG titers increase more slowly. This response is frequently not detectable for 4-6 wk, is highest months to years later during arthritis and may remain elevated for years after clinical remission $(2,11,12)$. Elevated total IgM levels, which are the best laboratory indicator of disease activity (13), correlate with specific IgM titers, but total IgG levels do not correlate with the specific IgG response (11).

Using immunoblots, Barbour et al. demonstrated spirochetal polypeptides that stimulate the IgG response in serum and joint fluid of patients with Lyme disease (14). In this study, in an effort to better understand the pathogenesis of the arthritis, we defined the sequence in which IgM and IgG antibodies appeared to each of the protein antigens of $B$. burgdorferi, and compared the antibody responses in serum and joint fluid. We report here the appearance of a new IgM response and the expansion of the IgG response late in the illness. These findings suggest that the Lyme spirochete persists for long periods in the host and triggers new immune responses during later attacks of arthritis.

\section{Methods}

Organisms. The isolate of B. burgdorferi used in this study was G 39/ 40 , which was originally cultured from Ixodes dammini ticks in Connecticut (2). This isolate was not cloned by limiting dilution and could be a mixture of more than one serotype. These organisms were maintained in continuous culture in fortified Kelly's medium (15) at $33^{\circ} \mathrm{C}$ in 13 $\times 100 \mathrm{~mm}$ sterile glass tubes (Pyrex, Corning Glassworks, Corning, NY). For immunoblot studies, bulk cultures were grown in 650 -ml tissue culture flasks to late log phase, as determined by dark field microscopy. Organisms were then pelleted by centrifugation at $10,000 \mathrm{~g}$ for $20 \mathrm{~min}$, washed once in cold $0.01 \mathrm{M}$ phosphate-buffered saline with $5 \mathrm{mM} \mathrm{MgCl}$ (PBS/Mg), centrifuged at $14,000 \mathrm{~g}$, resuspended in $\mathrm{PBS} / \mathrm{Mg}$ with glycerol $(15 \% \mathrm{vol} / \mathrm{vol})$, and frozen at $-70^{\circ} \mathrm{C}$ until ready for use.

Sera. Serial serum samples and joint fluids from patients with Lyme disease have been collected during the last nine years and frozen at $-70^{\circ} \mathrm{C}$ in our laboratory. For this study, we tested 86 sera and 9 joint fluid samples from patients with Lyme disease. These included acute and convalescent samples from 12 patients with mild disease (ECM alone), 11 of whom were treated with antibiotics. Acute specimens were obtained 1-3 wk after disease onset and convalescent samples were obtained 23 wk later. In 3 of the 12 patients, including the one who did not receive antibiotics, one or two postconvalescent samples were available that had been taken after $6 \mathrm{mo}$ to $4 \mathrm{yr}$ of remission. At the other end of the disease spectrum, six to nine serial samples were tested from six patients on whom sera were available throughout a prolonged and severe illness. Two of these patients had ECM followed by arthritis, three had ECM followed by neurologic abnormalities and then arthritis, and one had ECM followed by neurologic and cardiac involvement and then arthritis. The first serum available at the beginning of each manifestation was always included. Three of the six patients received penicillin therapy for ECM, but their disease progressed despite therapy. Simultaneous serum and joint fluid samples were available on four of the six patients, and five additional patients with single serum and joint fluid samples were 
evaluated. One of these five patients was treated with penicillin during ECM but still developed arthritis.

For comparison, we used four sera from normal subjects, six sera from patients with active rheumatic diseases (two patients each with rheumatoid arthritis, systemic lupus erythematosus, or Reiter's syndrome), and six sera from patients with other spirochetal infections (two patients with louse-borne relapsing fever and four with primary or secondary syphilis).

Sodium dodecyl sulfate-polyacrylamide electrophoresis (SDS-PAGE). Spirochetes were prepared for analysis with small modifications of the method described by Barbour (16). Frozen spirochetes were thawed, centrifuged for $2 \mathrm{~min}$ in a microfuge, and washed three times in cold PBS/Mg. The washed cells were resuspended in deionized water and adjusted to an OD of 0.100 when the mixture was assayed for protein content by the Bradford method (17). Aliquots of the suspension were then added to sample buffer to a final concentration of $2.0 \%$ SDS and $0.1 \mathrm{M}$ dithiothreitol. After boiling for $5 \mathrm{~min}, \sim 7.5 \mu \mathrm{g}$ of protein per lane were subjected to discontinuous SDS-PAGE (18) on $10.0 \%$ acrylamide gels. Separated polypeptides on the gels were stained with Coomassie Brilliant Blue R-250 or were transferred to nitrocellulose paper (Schleicher and Schuell, Keene, NH) as previously outlined (19). To assess the efficiency of transfer, one lane was cut from the paper and stained with amido black and compared to immunoblots. Molecular weight markers, labeled with ${ }^{125} \mathrm{I}$ by the lactoperoxidase method (20), were phosphorylase b $(94,000)$, bovine serum albumin $(67,000)$, ovalbumin $(43,000)$, carbonic anhydrase $(30,000)$, soybean trypsin inhibitor $(20,100)$, and lactalbumin $(14,400)$ (Pharmacia Fine Chemicals, Piscataway, NJ).

Detection of antigens on nitrocellulose paper. To saturate nonspecific protein-binding sites, the nitrocellulose paper containing transferred polypeptides was soaked in $0.01 \mathrm{M}$ PBS, $0.20 \%$ gelatin (PBS-gelatin) for $1 \mathrm{~h}$ at $25^{\circ} \mathrm{C}$. The nitrocellulose was then cut into strips representing individual lanes from the gel, and the strips were incubated individually with patient sera or joint fluids diluted in PBS-gelatin (1:50 for detection of IgM and 1:100 for detection of IgG) at $25^{\circ} \mathrm{C}$ for $2 \mathrm{~h}$ (for IgG) or $6 \mathrm{~h}$ (for IgM). The papers were washed four times in PBS-0.05\% Tween (PBS-Tween) and then probed for $1 \mathrm{~h}$ with affinity-purified ${ }^{125} \mathrm{I}$-labeled goat anti-human IgM (Fc-fragment specific) (Cooper Biomedical, Malvern, PA) for IgM detection or with ${ }^{125}$ I-labeled protein A (Pharmacia Fine Chemicals) for IgG detection. Both probes had been iodinated by the lactoperoxidase method (20) and were used at a specific activity of $1 \times 10^{5} \mathrm{cpm} / \mathrm{ml}$ of PBS-gelatin. The blots were once again washed four times in PBS-Tween, air-dried, and exposed to XRP-5 film (Eastman Kodak, Co., Rochester, NY).

Separation and quantitation of IgM in sera. Separation of IgM from IgG in sera was done with Sephacryl S300 and protein A Sepharose (both from Pharmacia Fine Chemicals) filtration. Serum $(1.5 \mathrm{ml})$ was filtered over an $S 300$ column $(2.6 \times 100 \mathrm{~cm})$ in PBS $(\mathrm{pH} \mathrm{7.3)}$ with continuous monitoring at an absorbance of $280 \mathrm{~nm}$ and a flow rate of $1.25 \mathrm{~cm}^{-2}$ $\mathrm{h}^{-1}$. 5-ml fractions were collected, and those containing the leading edge of the IgM peak were pooled and concentrated (CX 10 ultrafiltration units, Millipore Corp., Bedford, MA) to the original serum volume. The sample was then filtered over a 4-ml protein A Sepharose column at a flow rate of $0.15 \mathrm{ml} / \mathrm{min}$. After the void volume, the first peak was collected, concentrated, and its IgM content measured by radial immunodiffusion (LC-Partigan and Tri-Partigan Plates, Calbiochem-Behring Corp., La Jolla, CA). The sample was then adjusted to the concentration of IgM in the original serum sample and saved at $4^{\circ} \mathrm{C}$.

\section{Results}

Total spirochetal proteins. SDS-PAGE analysis of whole cell lysates of $B$. burgdorferi showed at least 29 components (Fig. 1, lane 1). A similar pattern was found after electrophoretic transfer of the polypeptides to nitrocellulose and staining with amido black (Fig. 1, lane 2). Antibodies of the IgG class from the sera

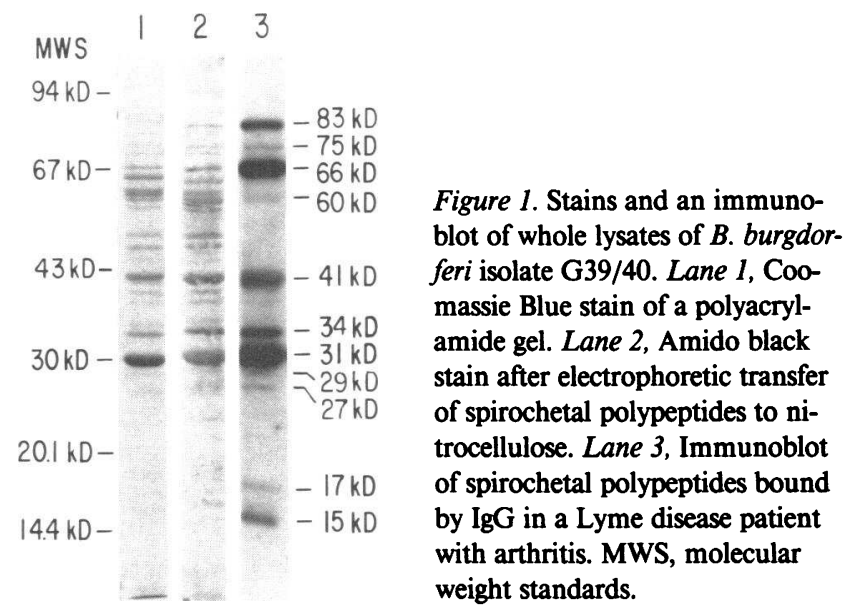

of patients late in the disease typically bound a maximum of 11 of these 29 polypeptides (Fig. 1, lane 3).

Immunoblots: patients with only ECM. Within 1 to 3 wk after disease onset, 6 of the 12 patients with ECM alone, of whom all but one received antibiotic therapy, developed antibodies of the IgM class that bound a polypeptide of $41 \mathrm{kD}$ as demonstrated by the example in Fig. $2 \mathrm{~A}$. By convalescence 23 wk later, 10 of the 12 had IgM antibodies to this antigen (Fig. $2 \mathrm{~A}$ ). At that time, a polypeptide of $83 \mathrm{kD}$ was also weakly bound by IgM in four of these patients, although not by the example in Fig. $2 \mathrm{~A}$. Only 3 of the 12 patients developed antibodies of the IgG class that bound the $41-\mathrm{kD}$ antigen, and it

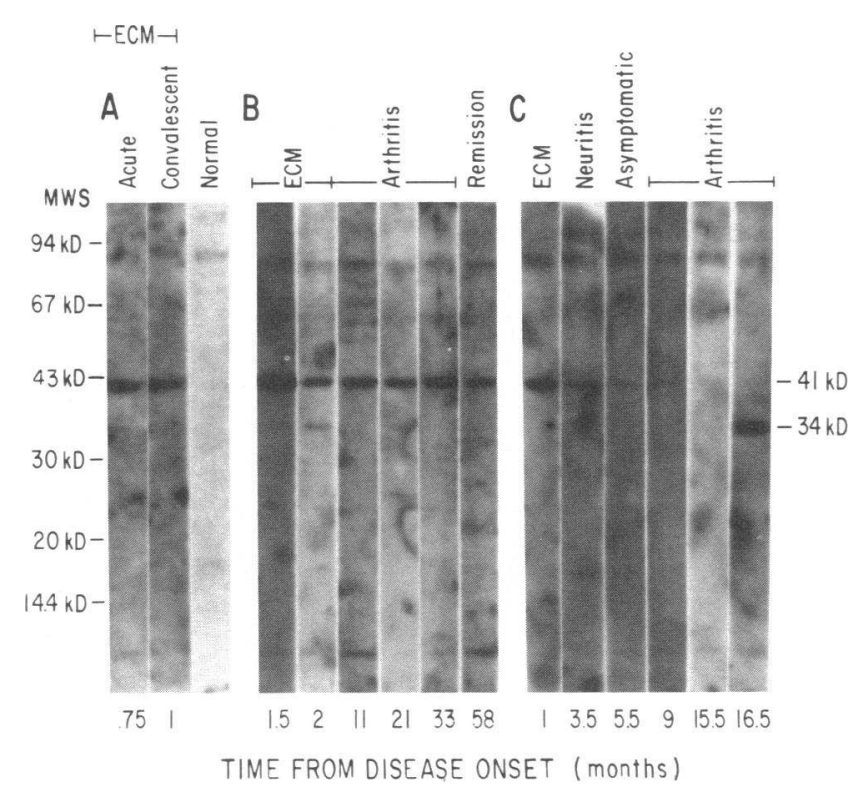

Figure 2. Immunoblot of IgM antibodies in serial serum samples from three representative patients with Lyme disease. Spirochetal polypeptides were electrophoretically transferred to nitrocellulose, probed with a 1:50 dilution of each serum, and bound IgM detected with ${ }^{125} \mathrm{I}-\mathrm{la}-$ beled affinity-purified anti-human IgM. (A) Patient with ECM alone. (B) Patient with ECM followed by arthritis. $(C)$ Patient with ECM followed by neurologic disease and then arthritis. Antigens commonly bound by IgM are shown. A normal serum immunoblotted in parallel is shown for comparison. 
typically required three or more weeks for this response to appear (Fig. $3 \mathrm{~A}$ ). In the three patients with postconvalescent samples, which included the one patient who did not receive antibiotic therapy, no protein antigens were bound in the samples obtained 6 mo to 4 yr after ECM. Patients with only ECM thus had an IgM response that was restricted to polypeptides of 41 , and to a lesser degree, $83 \mathrm{kD}$, a later IgG response that was limited to the $41-\mathrm{kD}$ antigen, and neither response was evident several months later.

Immunoblots: patients with prolonged disease. As shown by the examples in Fig. $2 B$ and $C$, during ECM all six of the patients with prolonged and severe disease also developed IgM antibodies that initially bound the $41-\mathrm{kD}$ antigen. During this period, three of them also bound weakly the component of $83 \mathrm{kD}$. In two of the six patients, the IgM response to the $41-\mathrm{kD}$ antigen persisted during arthritis, in one instance for 58 mo (Fig. $2 \mathrm{~B}$ ). 6 to 16 mo after onset of ECM, during arthritis, another two of the six patients had a new IgM response to a $34-\mathrm{kD}$ antigen (Fig. $2 \mathrm{C}$ ). Of five additional patients with arthritis on whom single serum specimens were available, two had strong binding by IgM antibodies to the $41-\mathrm{kD}$ polypeptide and one strongly bound the 34-kD structure. Two of the four patients with persistent binding to the $41-\mathrm{kD}$ antigen, one of the three with binding to the 34$\mathrm{kD}$ antigen, and one of the four with neither persistent nor late binding were treated with antibiotics during ECM. In patients with prolonged disease, the IgM response thus was characterized by initial and sometimes persistent binding of a 41-kD antigen followed sometimes by binding of a 34-kD antigen during arthritis.

In the group of six patients with prolonged disease tested serially, the IgG response developed in a typical sequential pattern to as many as 11 antigens. During ECM, the $41-\mathrm{kD}$ antigen was bound (Fig. 3, $B$ and $C$ ). 1-5 mo after disease onset, a response to components of 83 and $66 \mathrm{kD}$ developed in five of six patients (Fig. 3, $B$ and $C$ ), and antigens with molecular weights of 27 and $15 \mathrm{kD}$ were weakly bound in three patients. The same pattern of antibodies developed regardless of whether the patient had neurologic abnormalities, cardiac involvement, or migratory musculoskeletal pain.

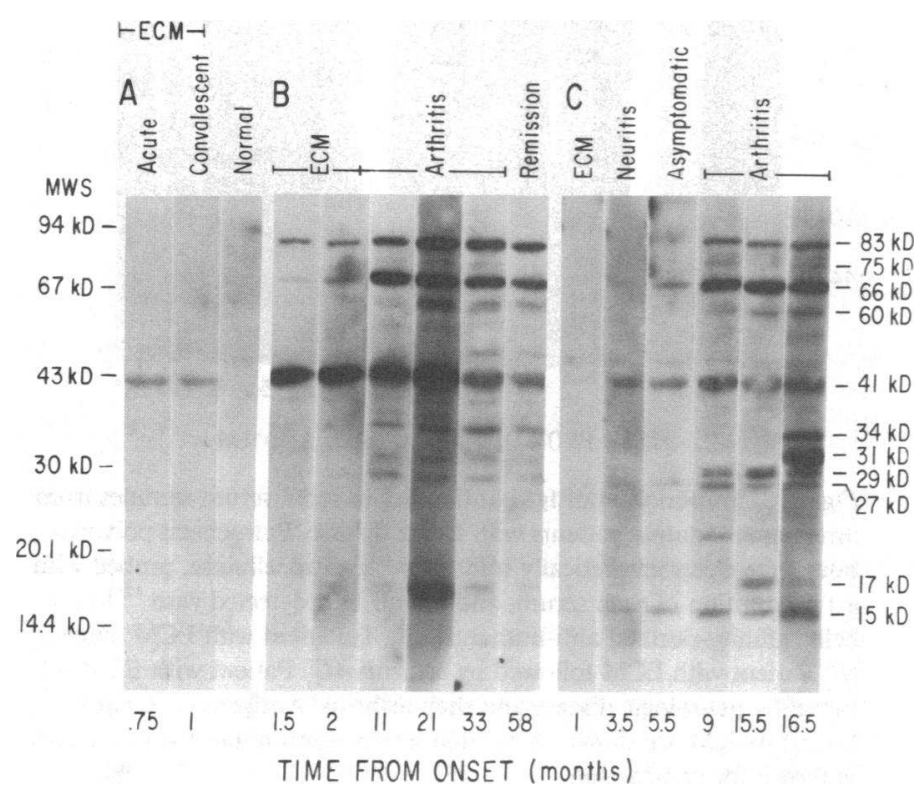

During the following months to years, after the onset of arthritis, two antigens of 75 and $60 \mathrm{kD}$ were bound weakly to moderately, and four antigens with molecular weights of 34,31 , 29 , and $17 \mathrm{kD}$ were bound strongly (Fig. $3, B$ and $C$ ). Of the latter four antigens, the $34-\mathrm{kD}$ component was identified by sera from all six patients, and the 31-, 29-, and 17-kD structures were bound by five. However, the onset of arthritis was not associated with the appearance of antibodies to a particular polypeptide. Of the five patients with arthritis in whom single sera were tested, all bound the 34-, 31-, and 29-kD antigens and four bound the 17-kD structure. The antibody response among the four penicillin-treated patients was similar to that of the seven untreated patients. The IgG response in prolonged Lyme disease thus was characterized by initial binding of only the $41-\mathrm{kD}$ antigen, followed in 1-3 mo by binding of the 83-, 66-, 27-, and 15-kD polypeptides, and then months to years later, by binding of the 75-, 60-, 34-, 31-, 29-, and 17-kD components. Once developed, IgG binding to each antigen typically persisted throughout the illness.

Simultaneous sera and joint fluids were obtained from nine patients with chronic Lyme arthritis. In all instances, IgM and IgG in both fluids bound identical components.

Immunoblots: control patients. Using the ${ }^{125}$ I-labeled goat anti-human IgM probe, the four normal control sera did not bind any spirochetal antigens (Fig. 4). Of the six rheumatic disease controls, one each of the sera from patients with SLE, rhematoid arthritis, or Reiter's syndrome bound very weakly the 41-kD polypeptide as demonstrated by the sample serum from a patient with rheumatoid arthritis (Fig. 4). A control serum from one patient with syphilis also bound this polypeptide very weakly, and serum from one patient with louse-borne relapsing fever bound it quite strongly (Fig. 4). None of the control subjects had IgG antibodies that bound any spirochetal antigens (Fig. 4).

Separation of IgM and IgG antibodies. To prove that the ${ }^{125}$ I-labeled anti-human IgM probe was detecting IgM during late disease, IgM and IgG antibodies were separated in two patient's sera by gel filtration. 16 mo after disease onset, whole serum from patient C (Figs. 2 and 3) and the IgM fraction of
Figure 3. Immunoblot of IgG antibodies in serial serum samples from the same three patients with Lyme disease as in Fig. 2. After electrophoretic transfer of spirochetal antigens, the nitrocellulose paper was probed with a 1:100 dilution of each serum and bound IgG detected by ${ }^{125}$ I-labeled protein A. Antigens commonly bound by IgG are shown. A normal serum immunoblotted in parallel is shown for comparison. 


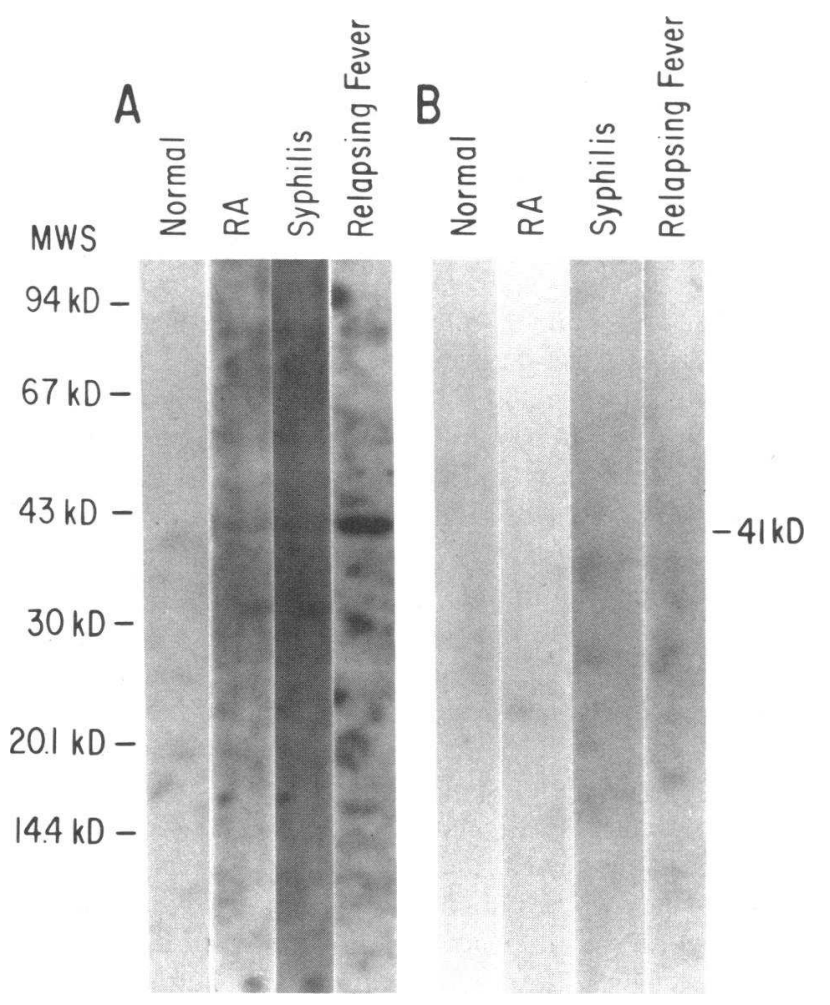

Figure 4. Immunoblot of $\operatorname{IgM}(A)$ and $\operatorname{IgG}$ antibodies $(B)$ from sera from four representative control patients. Immunoblots were performed as depicted in Figs. 2 and 3. RA, rheumatoid arthritis.

this serum detected the $34-\mathrm{kD}$ component of the spirochete when blotted with the ${ }^{125} \mathrm{I}$-labeled IgM probe (Fig. 5, lanes 2 and 4). This fraction did not contain detectable IgG antibodies, as shown by the lack of iodinated-protein A binding (Fig. 5, lane 3). Similarly, 33 mo after disease onset, serum from patient B (Figs. 2 and 3 ) and its IgM fraction still bound the $41-\mathrm{kD}$ polypeptide when reacted with the iodinated IgM probe, and this fraction did not contain detectable IgG.

\section{Discussion}

Antibody response in patients. In early Lyme disease, the initial IgM response was restricted to polypeptides of $41 \mathrm{kD}$, and to a

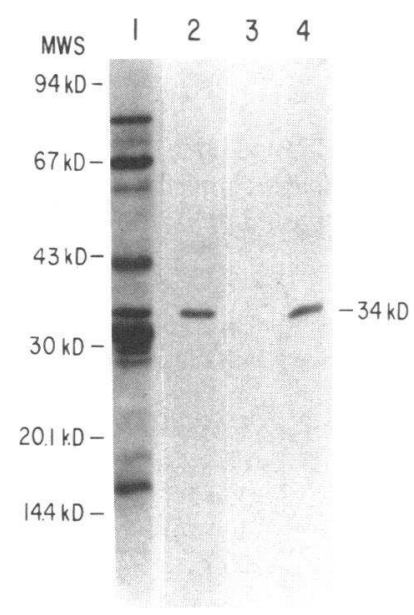

Figure 5. Immunoblots using serum and the IgM fraction of serum from patient $\mathrm{C}$ (Fig. 3) taken 16.5 mo after ECM. Serum was probed with ${ }^{125}$ I-labeled protein A (lane 1) and ${ }^{125} \mathrm{I}$-labeled anti-human IgM (lane 2). The IgM fraction of the same serum was then probed with ${ }^{125} \mathrm{I}$-labeled protein A (lane 3) and ${ }^{125}$ I-labeled anti-human IgM (lane 4). The $34,000-\mathrm{D}$ protein is shown. lesser degree, $83 \mathrm{kD}$ and the IgG response was limited to the 41 $\mathrm{kD}$ antigen. Specific IgM antibodies usually appeared within 13 wk after disease onset, and specific IgG antibodies generally required three or more weeks to develop. The delay in appearance of both specific IgM and IgG, shown here by immunoblots, is in agreement with previous studies of the antibody response done by indirect immunofluorescence and enzyme-linked immunosorbent assay (ELISA) $(2,11,12)$. Studies of cell-mediated immunity in Lyme disease have shown that spontaneous suppressor cell activity is increased during the first several weeks of infection, and after that time, the trend is toward less suppressor cell activity than normal (21). Immunosuppression early in the illness thus may limit the antibody response to only the most immunogenic polypeptides.

Although the number of patients with ECM alone and postconvalescent samples was small, the initial, restricted antibody response in these patients dampened and disappeared within several months, regardless of antibiotic therapy. In contrast, in patients with prolonged illness, the IgM response to the $41-\mathrm{kD}$ protein sometimes persisted for months to years, and late in the illness during arthritis, certain patients developed a new IgM response to a $34-\mathrm{kD}$ polypeptide. After initial binding of the 41$\mathrm{kD}$ antigen, the IgG response during the next 1-3 mo included binding of two to four more polypeptides followed during the next months to years by binding of four to six additional proteins. Barbour et al. demonstrated 11 spirochetal antigens of the same or similar molecular weight bound by IgG antibodies late in the illness $(14,22)$. Our analysis of serial sera in patients with different clinical manifestations did not reveal an association between arthritis and a particular polypeptide. Rather, progression of the disease was associated with gradual expansion of the immune response, regardless of the particular clinical manifestations and despite antibiotic therapy during ECM.

Since the IgM response seemed to be limited to two or three antigens, we were concerned that high-titered antibodies of the IgG class may have blocked the binding of lower affinity IgM to the other antigens. Furthermore, because the initial IgM response sometimes persisted and since a new IgM response sometimes appeared late in the illness, we wondered whether our iodinated anti-human IgM probe might have falsely bound the highly titered IgG antibodies. To answer these questions, we separated IgM and IgG antibodies from the sera of two patients late during the course of Lyme disease by two-stage column chromatography. Although $\mathrm{IgG}_{3}$ may not be totally removed by protein A binding used in the second column, these experiments suggested that the probe was specific for IgM and that the sera contained IgM antibodies to only the 41- and 34-kD structures.

Several possible mechanisms may explain the late appearance of IgM or IgG antibodies to spirochetal proteins, two of which, the 34- and $31-\mathrm{kD}$ polypeptides, have been shown to be part of the outer membrane of $B$. burgdorferi $(16,23)$. First, the immunosuppression of early Lyme disease may limit the $T$ celldependent antibody response until later in the disease. The period of immunosuppression usually lasts only for several weeks (21), however, and seems unlikely to explain the appearance of antibodies months or years into the illness. Second, patients may become reinfected. However, we think that this mechanism is very unlikely to explain the characteristic sequential pattern of antibody response observed in all six patients with prolonged disease. Third, certain polypeptides may be covered, perhaps by an extracellular slime layer, or hidden intracellularly until late in the illness. Although not convincingly demonstrated, patho- 
genic treponemes may have an outer layer that protects against host defenses (24), and such a layer has been postulated in $B$. burgdorferi (15). Finally, like other borrelia $(25,26)$, outer membrane proteins of $B$. burgdorferi may undergo antigenic variation. Like relapsing fever, Lyme arthritis is clinically a relapsing, remittent illness (27), and the $34-\mathrm{kD}$ polypeptide does show in vitro variation among isolates (23). However, an adequate animal model of Lyme disease is not yet available to test this hypothesis.

Late in the illness, the symptoms of Lyme disease are usually localized to joints, the synovium shows many plasma cells presumably capable of producing antibody locally (9), and immune complexes are usually found only in joints (28). Although synovium is not a selective barrier like the blood-brain barrier, we hypothesized that additional antigens may be bound by antibodies in joint fluid not present in serum. Among the nine patients tested, however, there were no qualitative differences in the paired joint fluid and serum responses. These results may be explained by movement of specific antibody either from serum to synovial tissue or vice versa.

Control patients. Among control patients, IgM antibodies that strongly bound the $41-\mathrm{kD}$ antigen were found in one of two patients with louse-borne relapsing fever. Weak IgM binding of this antigen was also seen in sera from three of the six patients with rheumatic diseases and from one patient with syphilis. None of the four normal subjects had either IgM or IgG antibodies reactive with $B$. burgdorferi. In contrast, Barbour et al. found crossreactive IgG antibodies in the sera of two of four patients with syphilis, in one instance against a 17-kD antigen and in the other against a $41-\mathrm{kD}$ protein (14). In addition, one of their two patients with relapsing fever had IgG antibodies to a $60-\mathrm{kD}$ polypeptide. The differences in the two studies are presumably due to different sera and to the small numbers of patients tested.

We expected to find crossreactive antibodies in the sera of patients with other spirochetal infections since $B$. burgdorferi is known to share antigens with certain other spirochetes (14). However, the meaning of the very weak binding to the $41-\mathrm{kD}$ antigen by IgM from sera of some patients with rheumatic disease is unknown. These patients were not from an endemic area for Lyme disease, and we do not think that they had asymptomatic infection with $B$. burgdorferi. Perhaps these are crossreactive antibodies from exposure to other spirochetes, possibly oral treponemes, or perhaps patients with certain rheumatic diseases occasionally make crossreactive IgM antibodies against this polypeptide. Sera from large numbers of patients with rheumatic disease will need to be tested to clarify this finding.

Comparison with other infections. The immune response to Treponema pallidum in syphilis has similarities to that in Lyme disease. During the first several weeks of leutic infection, the immune response is suppressed $(29,30)$, and the antibody response is restricted to a few polypeptides $(31,32)$. In tertiary syphilis, as in Lyme disease, specific IgM has been detected after the development of specific IgG, although the responsible antigens have not been identified in syphilis $(33,34)$. Similarly, in certain chronic parasitic infections, immunosuppression occurs in the illness (35), and specific IgM responses have been detected in the presence of specific IgG (35). No comparable information is available regarding infection with the relapsing fever borrelia.

In both syphilis and Lyme disease, serodiagnostic tests often give false-negative results early in the illness $(12,36,37)$. However, in syphilis, use of a flagellar-associated protein to which an early IgM response is directed (37), rather than a crude son- icate of spirochetes on the solid phase of an ELISA, improved the sensitivity of the test (36). This observation suggests that the 41-kD antigen of $B$. burgdorferi may give better results in an ELISA for early Lyme disease than the current test, which uses sonicated whole spirochetes $(11,12)$. Furthermore, in this study, IgM antibodies to the $41-\mathrm{kD}$ polypeptide were usually apparent by immunoblots before IgM titers were elevated by the current ELISA (12). Although antibodies reactive against this antigen may be present in patients with relapsing fever or syphilis (11, 14), these diseases can be distinguished clinically from Lyme disease and therefore should not cause diagnostic confusion. The binding of this antigen by IgM from rheumatic disease controls was typically very weak and could potentially be blocked to avoid false-positive results in this group of patients.

Implications regarding pathogenesis. Among immune-mediated diseases, it is of central importance whether a persistent infectious agent is necessary for continued disease activity or whether such an agent triggers disease, which is then followed by autoimmunity. Recent evidence-the demonstration of spirochetes by silver staining in the synovium of two of nine patients (38) and the response of approximately half of patients with arthritis to parenteral penicillin therapy (39)_suggest that the Lyme spirochete is alive in the joint during arthritis. Although the current study did not implicate a particular spirochetal antigen as important in the pathogenesis of the arthritis, the appearance of a new IgM response and the expansion of the IgG response late in the disease and the lack of such responses in patients with ECM alone further suggest that $B$. burgdorferi remains alive throughout the illness.

\section{Acknowledgments}

This study was supported in part by grants from the National Institutes of Health (AM-20358, AM-07107, RR-00125, and RR-05443) and the Arthritis Foundation and its Connecticut Chapter. Joseph E. Craft is a Pew Scholar in the Biomedical Sciences.

\section{References}

1. Burgdorfer, W., A. G. Barbour, S. F. Hayes, J. L. Benach, E. Grunwaldt, and J. P. Davis. 1982. Lyme disease-a tick-borne spirochetosis? Science (Wash. DC). 216:1317-1319.

2. Steere, A. C., R. L. Grodzicki, A. N. Kornblatt, J. E. Craft, A. G. Barbour, W. Burgdorfer, G. P. Schmid, E. Johnson, and S. E. Malawista. 1983. The spirochetal etiology of Lyme disease. N. Engl. J. Med. 308: 733-740.

3. Benach, J. L., E. M. Bosler, J. P. Hanrahan, J. L. Coleman, G. S. Habicht, T. F. Bast, D. J. Cameron, J. L. Ziegler, A. G. Barbour, W. Burgdorfer, R. Edelman, and R. A. Kaslow. 1983. Spirochetes isolated from the blood of two patients with Lyme disease. N. Engl. J. Med. 308: 740-742.

4. Steere, A. C., S. E. Malawista, J. A. Hardin, S. Ruddy, P. W. Askenase, and W. A. Andiman. 1977. Erythema chronicum migrans and Lyme arthritis: the enlarging clinical spectrum. Ann. Intern. Med. 86:685-698.

5. Steere, A. C., N. H. Bartenhagen, J. E. Craft, G. J. Hutchinson, J. H. Newman, D. W. Rahn, L. H. Sigal, P. N. Spieler, K. S. Stenn, and S. E. Malawista. 1983. The early clinical manifestations of Lyme disease. Ann. Intern. Med. 99:76-82.

6. Steere, A. C., W. P. Batsford, M. Weinberg, J. Alexander, H. J. Berger, S. Wolfson, and S. E. Malawista. 1980. Lyme carditis: cardiac abnormalities of Lyme disease. Ann. Intern. Med. 93:8-16.

7. Reik, L., A. C. Steere, N. H. Bartenhagen, R. E. Shope, and S. E. Malawista. 1979. Neurologic abnormalities of Lyme disease. Medicine (Baltimore). 58:281-294. 
8. Pachner, A. R., and A. C. Steere. 1985. The triad of neurologic manifestations of Lyme disease: meningitis, cranial neuritis, and radiculoneuritis. Neurology. 35:47-53.

9. Steere, A. C., A. Gibofsky, M. E. Patarroyo, R. J. Winchester, J. A. Hardin, and S. E. Malawista. 1979. Chronic Lyme arthritis: clinical and immunogenetic differentiation from rheumatoid arthritis. Ann. Intern. Med. 90:896-901.

10. Steere, A. C., C. E. Brinckerhoff, D. J. Miller, H. Drinker, E. D. Harris, Jr., and S. E. Malawista. 1980. Elevated levels of collagenase and prostaglandin E2 from synovium associated with erosion of cartilage and bone in a patient with chronic Lyme arthritis. Arthritis Rheum. 23:591599.

11. Craft, J. E., R. L. Grodzicki, and A. C. Steere. 1984. Antibody response in Lyme disease: evaluation of diagnostic tests. J. Infect. Dis. 149:789-795.

12. Shrestha, M., R. L. Grodzicki, and A. C. Steere. 1985. Diagnosing early Lyme disease. Am. J. Med. 78:235-240.

13. Steere, A. C., J. A. Hardin, S. Ruddy, J. G. Mummaw, and S. E. Malawista. 1979. Lyme arthritis: correlation of serum and cryoglobulin IgM with activity, and serum IgG with remission. Arthritis Rheum. 22:471-483.

14. Barbour, A. G., W. Burgdorfer, E. Grunwaldt, and A. C. Steere. 1983. Antibodies of patients with Lyme disease to components of the Ixodes dammini spirochete. J. Clin. Invest. 72:504-515.

15. Barbour, A. G. 1984. Isolation and cultivation of Lyme disease spirochetes. Yale J. Biol. Med. 57:521-525.

16. Barbour, A. G., S. L. Tessier, and W. J. Todd. 1983. Lyme disease spirochetes and ixodid tick spirochetes share a common surface antigenic determinant defined by a monoclonal antibody. Infect. Immun. 41:795804.

17. Bradford, M. M. 1976. A rapid and sensitive method for the quantitation of microgram quantities of protein utilizing the principle of protein-dye binding. Anal. Biochem. 72:248-254.

18. Laemmli, U. K. 1970. Cleavage of structural proteins during the assembly of the head of bacteriophage T4. Nature (Lond.). 227:680-685.

19. Towbin, H., T. Staehelin, and J. Gordon. 1979. Electrophoretic transfer of proteins from polyacrylamide gels to nitrocellulose sheets: procedure and some applications. Proc. Natl. Acad. Sci. USA. 76:43504354.

20. Phillips, D. R., and M. Morrison. 1971. Exposed protein in the intact human erythrocyte. Biochemistry. 10:1766-1771.

21. Moffat, C. M., L. S. Sigal, A. C. Steere, D. H. Freeman, and J. M. Dwyer. 1984. Cellular immune findings in Lyme disease: correlation of serum IgM and disease activity. Am. J. Med. 77:625-632.

22. Barbour, A. G. 1984. Immunochemical analysis of Lyme disease spirochetes. Yale J. Biol. Med. 57:581-586.

23. Barbour, A. G., S. L. Tessier, and S. F. Hayes. 1984. Variation in a major surface protein of Lyme disease spirochetes. Infect. Immun. 45:94-100.

24. Fitzgerald, T. J. 1983. Attachment of treponemes to cell surfaces.
In Pathogenesis and Immunology of Treponemal Infections. R. F. Schell and D. M. Musher, editors. Marcel Dekker, Inc., New York and Basel. 195-227.

25. Coffey, E. M., and W. C. Eveland. 1967. Experimental relapsing fever initiated by Borrelia hermsii. II. Sequential appearance of major serotypes in the rat. J. Infect. Dis. 117:29-34.

26. Stoenner, H. G., T. Dodd, and C. Larsen. 1982. Antigenic variation of Borrelia hermsii. J. Exp. Med. 156:1297-1311.

27. Steere, A. C., S. E. Malawista, N. H. Bartenhagen, P. N. Spieler, J. H. Newman, D. W. Rahn, G. J. Hutchinson, J. Green, D. R. Snydman, and E. Taylor. 1984. The clinical spectrum and treatment of Lyme disease. Yale J. Biol. Med. 57:453-461.

28. Hardin, J. A., A. C. Steere, and S. E. Malawista. 1979. Immune complexes and the evolution of Lyme arthritis: dissemination and localization of abnormal Clq binding activity. N. Engl. J. Med. 301:13581363.

29. Musher, D. M., R. F. Schell, R. H. Jones, and A. H. Jones. 1975. Lymphocyte transformation in syphilis: an in vitro correlate of immune suppression in vivo? Infect. Immun. 11:1261-1264.

30. Pavia, C. S., J. D. Folds, and J. B. Baseman. 1978. Cell-mediated immunity during syphilis: a review. Br. J. Vener. Dis. 54:144-150.

31. Hanff, P. A., T. E. Fehniger, J. N. Miller, and M. A. Lovett. 1982. Humoral immune response in human syphilis to polypeptides of Treponema pallidum. J. Immunol. 129:1287-1291.

32. Moskophidis, M., and F. Muller. 1984. Molecular analysis of immunoglobulins $M$ and $G$ immune response to protein antigens of Treponema pallidum in human syphilis. Infect. Immun. 43:127-132.

33. O'Neill, P., and C. S. Nichol. 1972. IgM class antitreponemal antibody in treated and untreated syphilis. Br. J. Vener. Dis. 48:460463.

34. Wilkinson, A. E., and P. Rodin. 1976. IgM-FTA test in syphilis in adults. Its relation to clinical findings. Br. J. Vener. Dis. 52:219-223.

35. Hoffman, S. L., W. F. Piessens, S. Ratiwayante, P. R. Hussein, L. Kurniawan, P. W. Piessens, J. R. Campbell, and H. A. Marwoto. 1984. Reduction of suppressor T lymphocytes in the tropical splenomegaly syndrome. $N$. Engl. J. Med. 310:337-341.

36. Pedersen, N. S., C. S. Petersen, M. Vejtorp, and N. H. Axelsen. 1982. Serodiagnosis of syphilis by enzyme-linked immunosorbent assay for IgG antibodies against the Reiter treponeme flagellum. Scand. J. Immunol. 15:341-348.

37. Pedersen, N. S., C. S. Petersen, and N. H. Axelsen. 1982. Enzymelinked immunosorbent assay for detection of immunoglobulin $\mathrm{M}$ antibody against the Reiter treponeme flagellum in syphilis. J. Clin. Microbiol. 16:608-614.

38. Johnston, Y. E., P. H. Duray, A. C. Steere, M. Kashgarian, J. Buza, S. E. Malawista, and P. W. Askenase. 1985. Lyme arthritis: Spirochetes found in synovial microangiopathic lesions. Am. J. Pathol. 118: 26-34.

39. Steere, A. C., J. Green, R. T. Schoen, E. Taylor, G. J. Hutchinson, D. W. Rahn, and S. E. Malawista. 1985. Successful parenteral penicillin therapy of established Lyme arthritis. N. Engl. J. Med. 312:869-874. 